\title{
Umbilical Artery and Middle Cerebral Artery and Cerebroplacental Ratio for Doppler Indices' Reference Ranges
}

\author{
ARJUAMND SULTANA 1 , MUHAMMAD NAWAZ ANJUM ${ }^{2}$, NAVEED ASAD ${ }^{3}$, RIZWAN UL HAQ ${ }^{4}$, TAIMOOR SHAHID \\ QUDSIA SADAF 6 , AMINA TARIQ7 \\ ${ }^{1}$ Radiology Research Section faculty of Allied Health sciences, The University of Lahore \\ ${ }^{2}$ Head Of Department, Radiology Research Section faculty of Allied Health sciences, The University of Lahore \\ ${ }^{3}$ Assistant Professor, Radiology Research Section faculty of Allied Health sciences, The University of Lahore \\ ${ }^{4}$ Senior Medical officer, DHQ Hospital Kasur, Belarusian State Medical University, Russia \\ ${ }^{5}$ Medical Officer, Govt. Aziz Bibi THQ Hospital Roshan Bheela Kasur, Weifang medical University, China \\ ${ }^{6}$ Postgraduate Resident, Department of Orthodontics, University College of Medicine \& Dentistry, University of Lahore \\ ${ }^{7}$ Postgraduate Research coordinator, Research cell, University College of Medicine \& Dentistry, University of Lahore \\ Correspondence to Amna Tariq, Email id: aminatariq8@gmail.com Cell:0336-0333108
}

\begin{abstract}
Aim: To investigate the reference values of Doppler indices for umbilical artery and Middle Cerebral Artery as well as Cerebro-placental Ratio and specifically, to evaluate the quality of methodology used on which these reference values are grounded, with the help of already established quality standards for research design, statistical analysis as well as methods of results reporting.

Methodology: The methodological quality of the full-text versions of eligible studies was assessed independently by the same reviewers and a medical statistician (E.S.U.). Disagreements were resolved by consensus or consultation with two other reviewers (A.T.P. and E.F.). Quality criteria for evaluation methodologies of the published articles was developed which was based on the already available research publication ${ }^{25,36,37}$. The methodology evaluation criteria was segregated into two levels, one is study design and the other one is statistics used as well as its reporting methods. Total no. of criteria of quality were 24 to be evaluated.

Results: Generally, methodological quality score was parallel for the research articles designed to evaluate umbilical artery range (median 42\%; range 13.8-63.8\%). For the studies focusing on middle cerebral artery range showed a median of $48 \%$ with a Class interval of $22.1-72.1 \%$ whereas the median score of cerebroplacental ratio was $47.1 \%$ with a Class interval of $34.6-55.5 \%$.

Conclusion: Rigorous methodology of this review study is the major strength, which is consisted of a standard and well developed methodology of scoring the quality of studies according to their methodology selection as well as the statistical analysis and the level of its interpretation.

Keywords: Umbilical artery, Middle Cerebral Artery, Cerebro-placental Ratio, Doppler indices
\end{abstract}

\section{INTRODUCTION}

The assessment of small-for-gestational-age is done by using doppler velocimetry as this assessment helps in evaluating the prenatal risk factors which may results in negative outcome ${ }^{1}$. Diseases of placenta have been proved to be linked with umbilical artery anomalies as assessed by Doppler velocimetry ${ }^{2}$. Redistribution of blood flow, hypoxia, occurring in fetus depict the cardiovascular adaptations which could be assessed by evaluating alterations in the middle cerebral artery of fetus ${ }^{3-5}$. Therefore, in the intrauterine growth restriction context, it is important to consider declined pulsatility index to prevent brain damage in fetus ${ }^{6-9}$. Literature has proposed that the middle cerebral artery-pulsativity index to umbilical artery-Pulsativity index, and the cerebroplacental ratio independently predict the fetal anomalies ${ }^{10}$ as well as Csection ${ }^{11,12}$ along with the negative affects at perinatal level. ${ }^{13}$ 16 So, for the alterations in planning of antepartum investigations and compromised fetus delivery in few conditions, CPR and Doppler indices of middle cerebral artery as well as umbilical artery is currently in use ${ }^{2,10}$. At the same time as the standardization of fetal Doppler signals obtaining methods has been attained ${ }^{17}$, numerous reference ranges have been stated as well as the characterization of Doppler progression patterns ${ }^{18-22}$.

Hence, literature evident that indication of high risk of fetal demise has clearly been done by qualitative alterations in

Received on 13-02-2021

Accepted on 23-06-2021
Doppler indices of umbilical artery, for example, the incidence, deficiency or reversal of end-diastolic velocity. ${ }^{23-25}$ Whereas, the relationship among the quantitative alterations of doppler indices with regards to middle cerebral artery and umbilical artery, changes recorded using pulsativity index as well as perinatal results and future consequences are not standardized yet. ${ }^{26-28}$ Moreover, appropriate or increased gestational age fetuses' Doppler indices as well as postterm pregnancy ${ }^{29}$, problems in pregnancy being diabetic ${ }^{30}$, and normal dichorionic twin pregnancy ${ }^{31}$ are not yet explored ${ }^{32}$. So, it was hypothesized that this evidence lacking may be elucidated to some extent by various Doppler indices to investigate the normal or abnormal results, based on a latest systematic review of indices estimations for fetal biometry ${ }^{33}$.

Current study aimed to investigate the reference values of Doppler indices for umbilical artery and Middle Cerebral Artery as well as Cerebro-placental Ratio and specifically, to evaluate the quality of methodology used on which these reference values are grounded, with the help of already established quality standards for research design, statistical analysis as well as methods of results reporting.

\section{METHODS}

The planning and conduction of current study was based in accordance with MOOSE group checklist and PRISMA statement for systematic review reporting after approval from Institutional Review Board.

Eligibility criteria, information sources and search strategy: After formulating search strategy with the help of 
Professional information specialist. Google scholar, MEDLINE and Web of Science databases were targeted to explore the relevant studies reported from 2017 to 2020 . For exploration of more relevant articles, bibliography of all the articles was examined. English language was consider as medium of selected published articles.

Inclusion criteria: Studies in which reference ranges were made for Doppler indices for middle cerebral artery, and umbilical artery as well as Cerebroplacental ratio were included based on observational research design.

Exclusion criteria: Case control studies were excluded if the objective of those studies was other than construction of ranges for Doppler reference ranges as well as the studies were limited to the gestational period greater than 20 weeks or Less than 40 weeks.

Methodological quality assessment: The same medical statistician and reviewers assessed the methodological quality independently in terms of entire-text versions of appropriate research papers. With the mutual consensus or by taking second opinion from supervisor. Quality criteria for evaluation methodologies of the published articles was developed (Table 1 and Table 2) ${ }^{38}$ which was based on the already available research publication. 25,36,37 The methodology evaluation criteria was segregated into two levels, one is study design and the other one is statistics used as well as its reporting methods. Total no. of criteria of quality were 22 to be evaluated.

Data extraction: After reviewing the research studies selected according to inclusion/exclusion criteria, data was entered in MS Excel 2013. Evaluation of studies was done by considering the quality assessment criteria for methodologies developed earlier and on that bases the score was assigned 0 or 1 whereas 0 mean higher risk of biasness and 1 means low risk of biasness. The scoring was by taking score of all the possible scores ranges between 0-24. Inter-rater reliability was assessed to make sure the data reliability which was 0.751 $(75.1 \%)$ that means a good reliability of the evaluated data.

Data analysis: After entering data in SPSS version 23.0, Median score and frequency (percentages) were calculated.

Table 1: Domains based on study design and measurement criteria of risk bias ${ }^{38}$

\begin{tabular}{|c|c|c|}
\hline Domain & $\begin{array}{c}\text { Low Kisk Bias } \\
\end{array}$ & $\begin{array}{r}\text { High Kisk Bias } \\
\end{array}$ \\
\hline \multirow[t]{2}{*}{ Design } & $\begin{array}{l}\text { Clearly described as either cross- } \\
\text { sectional or }\end{array}$ & Not reported \\
\hline & Iongitudinal & $\begin{array}{l}\text { Mixture of cross-sectional and } \\
\text { longitudinal data }\end{array}$ \\
\hline \multirow[t]{2}{*}{ Population } & $\begin{array}{l}\text { Women reported as coming from } \\
\text { population of low }\end{array}$ & $\begin{array}{l}\text { Women from unselected } \\
\text { population; or selected; or at }\end{array}$ \\
\hline & risk of pregnancy complications & $\begin{array}{c}\text { high risk of pregnancy } \\
\text { complications; or not reported }\end{array}$ \\
\hline $\begin{array}{l}\text { Prospective data } \\
\text { collection }\end{array}$ & $\begin{array}{l}\text { Prospective study and ultrasound data } \\
\text { collected specifically for purpose of } \\
\text { constructing charts of fetal Doppler }\end{array}$ & $\begin{array}{l}\text { Retrospective study, data not } \\
\text { collected specifically for purpose of } \\
\text { constructing charts of fetal Doppler, } \\
\text { or unclear (e-E. use of routinely } \\
\text { collected data) }\end{array}$ \\
\hline Specific scan & Specific scan for research purposes & $\begin{array}{l}\text { Routine scan in context of } \\
\text { pregnancy assessment }\end{array}$ \\
\hline Sample size & $\begin{array}{l}\text { A-priori determination or calculation of } \\
\text { sample size and justification }\end{array}$ & $\begin{array}{l}\text { Iack of a-priori sample size } \\
\text { determination or calculation and } \\
\text { justification }\end{array}$ \\
\hline Recruitment period & Reported & Not reported \\
\hline $\begin{array}{l}\text { Consecutive } \\
\text { enrolment }\end{array}$ & Consecutively included patients & $\begin{array}{l}\text { Did not include patients } \\
\text { consecutively }\end{array}$ \\
\hline $\begin{array}{l}\text { Inclusion/exclusion } \\
\text { criteria }\end{array}$ & 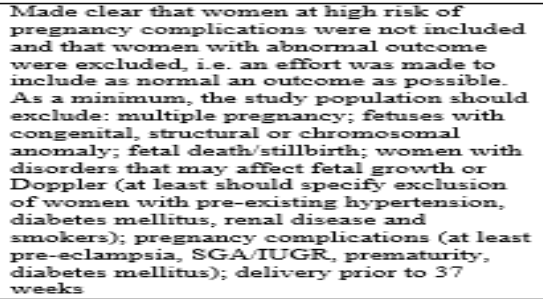 & $\begin{array}{l}\text { Study population included both low- } \\
\text { and hiph-risk pregnancies, or women } \\
\text { with abmormal outcome were not } \\
\text { excluded. Study population did not } \\
\text { exclude fetuses or preanamcies with } \\
\text { the characteristics described in the } \\
\text { 'low risk' column Exclusions which } \\
\text { would have a direct effect on the } \\
\text { Doppler, such as fetuses found at } \\
\text { birth to be small for dates }\end{array}$ \\
\hline $\begin{array}{l}\text { Method of dating } \\
\text { pregnancy }\end{array}$ & $\begin{array}{l}\text { Clearly described known IMP and } \\
\text { sonogram before } 14 \text { weeks " gestation } \\
\text { demonstrating crown-rump length that } \\
\text { corroborates INP dates (within how many } \\
\text { days unspecified) }\end{array}$ & 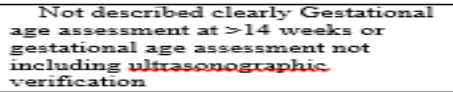 \\
\hline Multicenter study & $\begin{array}{l}\text { Study performed with more than one } \\
\text { center collaborating }\end{array}$ & Performed at only one hospital \\
\hline
\end{tabular}

Table 2: Domains based on Statistical methods and reporting and measurement criteria of risk bias ${ }^{38}$

\begin{tabular}{|c|c|c|}
\hline Domain & Low Risk Bias & High Risk Bias \\
\hline Perinatal outcome & Collected and reported prospectively & Not reported \\
\hline Gestational age range & Reported & Not reported \\
\hline $\begin{array}{l}\text { Ultrasound machines and } \\
\text { probe type used }\end{array}$ & Clearly specified & Not clearly specified \\
\hline Reported sonographers & Number of sonographers reported & Not clearly specified \\
\hline Sonographer experience & $\begin{array}{l}\text { Experienced or specifically trained } \\
\text { sonographers clearly reported }\end{array}$ & Not clearly specified \\
\hline Blinded measurements & Sonographers were blinded & Not clearly specified \\
\hline $\begin{array}{l}\text { Ultrasound machines quality } \\
\text { control measures }\end{array}$ & $\begin{array}{l}\text { Should include the following: } \\
\text { assessment of intra-observer } \\
\text { variability; assessment of inter- } \\
\text { observer variability; image review; } \\
\text { image scoring; image storage }\end{array}$ & $\begin{array}{l}\text { Does not contain } \\
\text { quality control measures }\end{array}$ \\
\hline Protocol & $\begin{array}{l}\text { Study described sufficient and } \\
\text { unambiguous details of measurement } \\
\text { techmiques used for fetal Doppler } \\
\text { parameters }\end{array}$ & $\begin{array}{l}\text { Study did not describe } \\
\text { sufficient and } \\
\text { unambiguous details of } \\
\text { measurement techniques } \\
\text { used for fetal Doppler } \\
\text { parameters }\end{array}$ \\
\hline $\begin{array}{l}\text { Number of measurements } \\
\text { taken for each Doppler } \\
\text { variable }\end{array}$ & $\begin{array}{l}\text { At least three measures per fetus per } \\
\text { scan }\end{array}$ & $\begin{array}{l}\text { Single measure or not } \\
\text { specified }\end{array}$ \\
\hline Angle correction & Clearly specified & Not clearly specified \\
\hline
\end{tabular}




\section{RESULTS}

Total number of articles found were 152 published articles among which only 35 articles were deliberated for inclusion. A total of 10 articles met the inclusion criteria which were used to assess the methodological quality at predefined criteria. ${ }^{39-48}$

Mean score of all the research articles included in the current study was $49.7 \%$ (95\%, Cl, 45.1-54.1\%). For the study design along with statistics used and the way of reporting, the quality assessment mean scores were 45.7 (95\% Cl, 40.9-50.4\%) and $52.6 \%(95 \% \mathrm{Cl}, 47.1-58 \%)$, respectively. The most primitive research was published in $2017^{48}$ and the latest in 2020.48

Sample size median score was 156 women. On the other hand, the ultrasound examination's median score was 258. Umbilical artery reference ranges were mentioned in 4 studies, reference ranges for Doppler of Middle cerebral artery was reported in 3 studies. In 3 studies, both Umbilical and middle cerebral artery Doppler reference ranges were reported, whereas only 2 studies reported cerebroplacental ratio. Pulse index was given in 4 studies. Generally, methodological quality score was parallel for the research articles designed to evaluate umbilical artery range (median 42.0\%; range 13.8$63.8 \%$ ). For the studies focusing on middle cerebral artery range showed a median of $48.0 \%$ with a Class interval of
$22.1-72.1 \%$ whereas the median score of cerebroplacental ratio was $47.1 \%$ with a Class interval of $34.6-55.5 \%$.

Prospective research studies were 8 . 1 study was longitudinal in nature, whereas 7 studies were crossectional in nature. $5(50 \%)$ studies included low risk pregnancies, whereas about $60 \%$ of the total included studies, dating method was used which was considered in low risk of biasness.

In studies focused on umbilical artery, Doppler ranges of middle cerebral artery and cerebroplacental ratio were parallel with each other in terms of highest risk of bias. It was noted that studies were lacking "multicenter study" in which only 2 studies were conducted in more than one center, quality control measures for ultrasound; only 1 study reported a proper strategy for quality control. Sonographic experience was not mentioned in even a single study. The training or experience of sonographer was clearly mentioned in five studies. no study has mentioned the blinded measurements in which sonographer was not known about the recorded measurements at the time of ultrasound examination and only 4 studies mentioned number of measurements taken. Recruitment method was not clear in most of the studies.

Even though few separate 'inclusion/exclusion criteria' of subjects (item 1.08) were utilized in studies, but no research study was having a systematic use of these criteria. Along with this, only $3(30 \%)$ studies mention 'sample size' calculation.

Graph 1: Methodological quality assessment score percentage extracted from 4 studies reported umbilical artery reference ranges

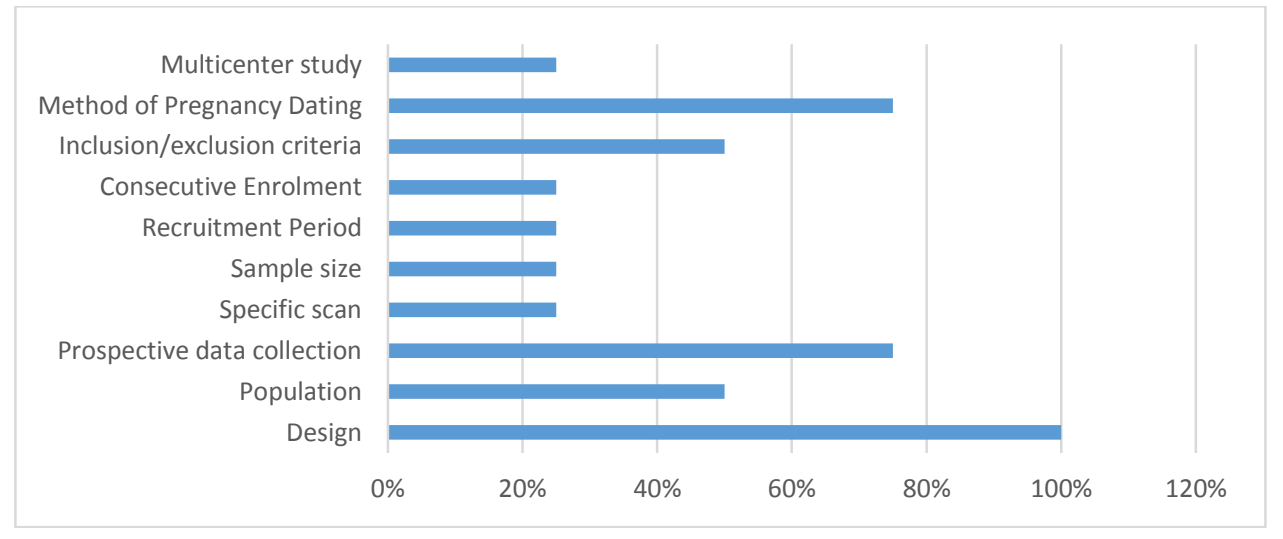

Graph 2: Statistical analysis and reporting Quality score percentage extracted from 4 studies reported umbilical artery reference ranges

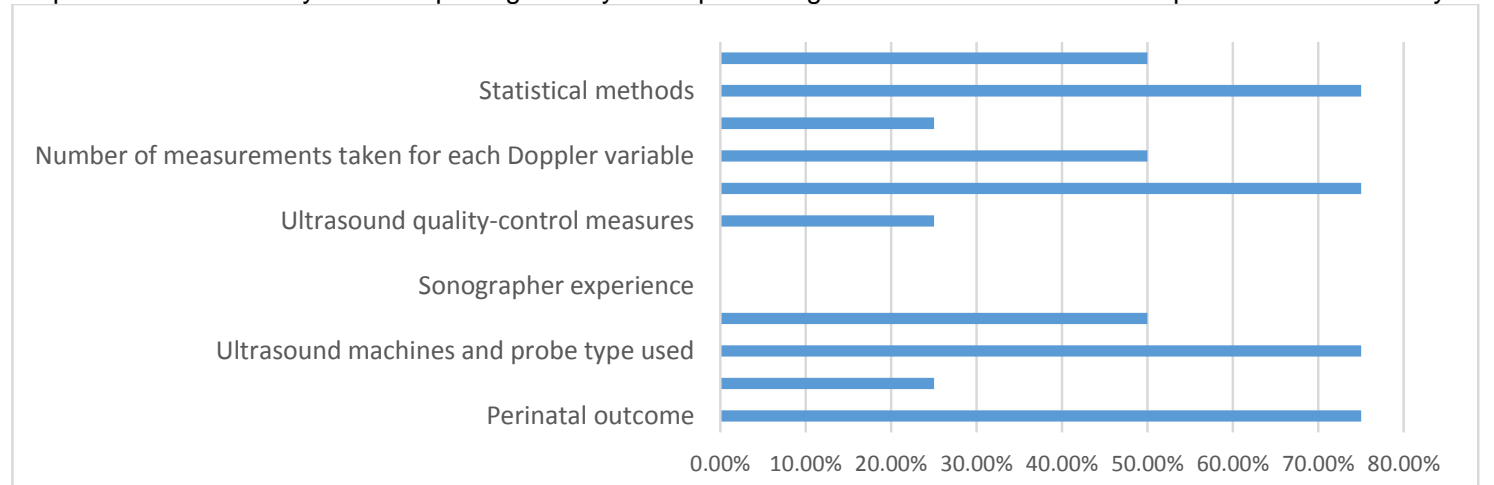


Graph 3: Methodological quality assessment score percentage extracted from 3 studies reported fetal middle cerebral artery reference ranges

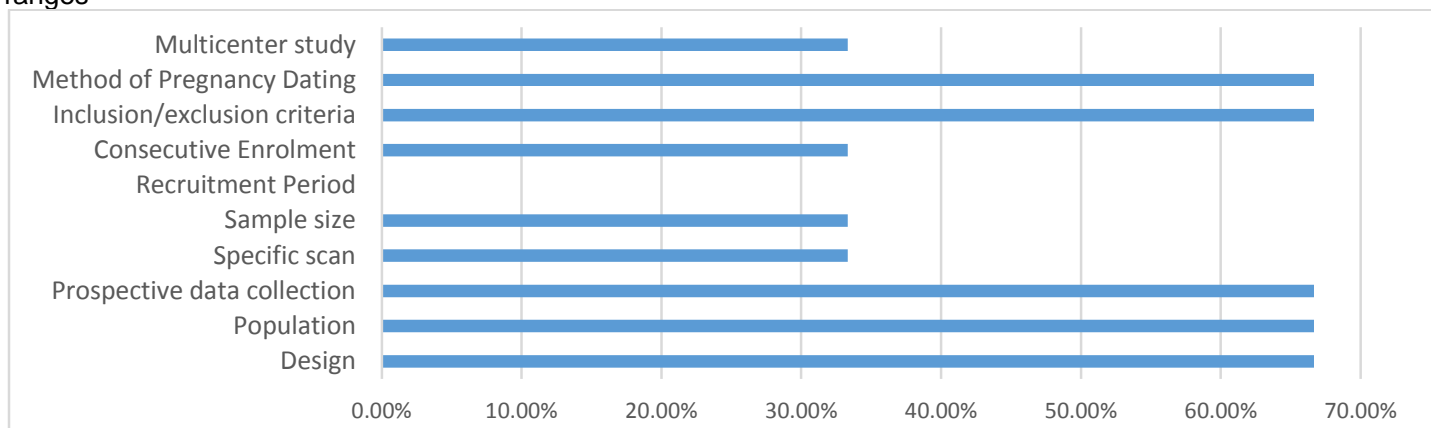

Graph 4: Statistical analysis and reporting Quality score percentage extracted from 3 studies reported fetal middle cerebral artery reference ranges

Statistical methods

Number of measurements taken for each Doppler variable

Ultrasound quality-control measures

Sonographer experience

Ultrasound machines and probe type used

Perinatal outcome

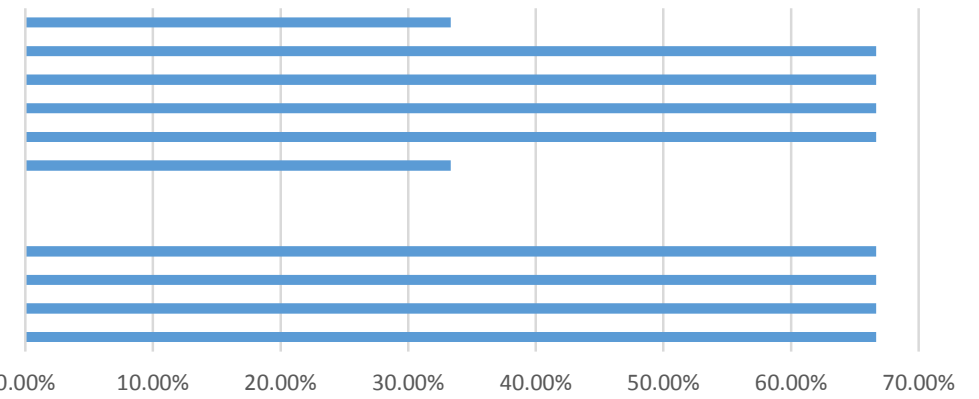

Graph 5: Methodological quality assessment score percentage extracted from 3 studies reported fetal middle cerebral artery reference ranges

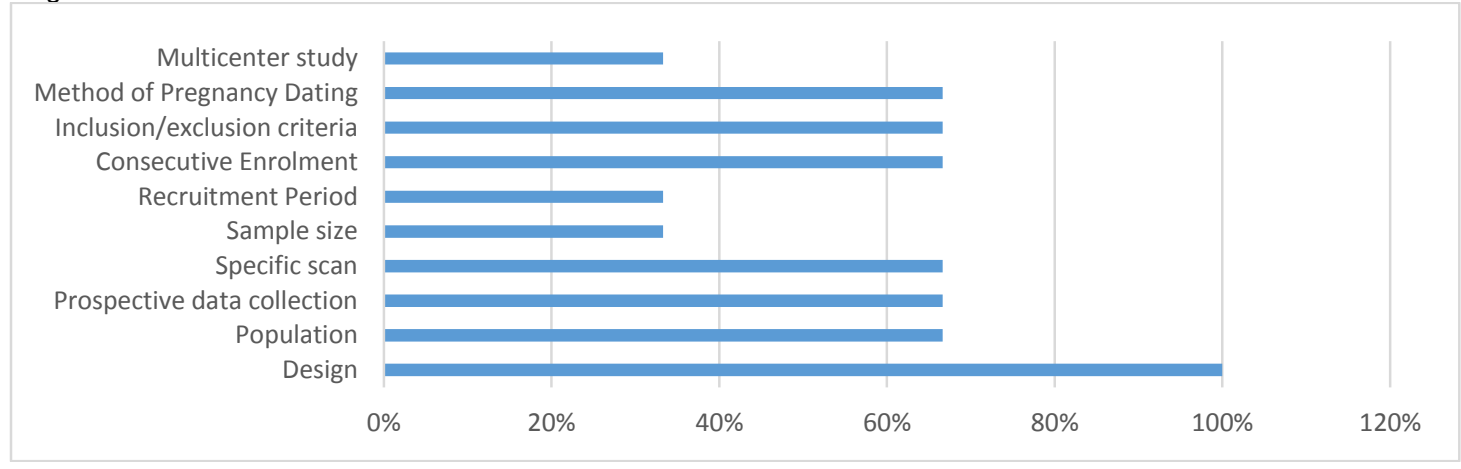

Graph 6: Statistical analysis and reporting Quality score percentage extracted from 3 studies reported fetal middle cerebral artery reference ranges

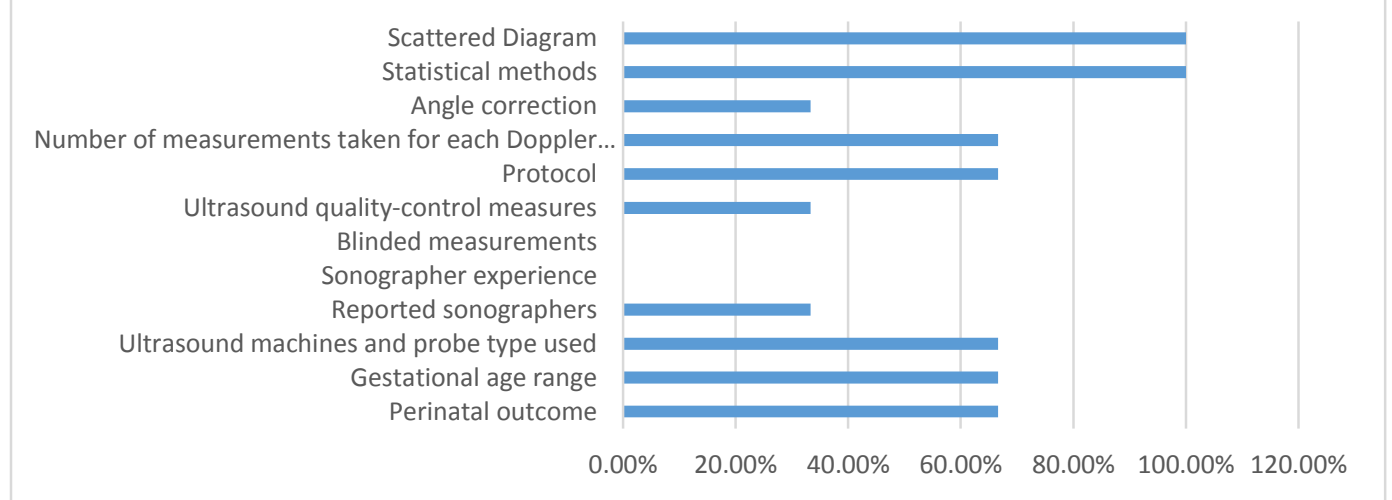




\section{DISCUSSION}

The aim of the study was to investigate the reference values of Doppler indices for umbilical artery and Middle Cerebral Artery as well as Cerebro-placental Ratio and specifically, to evaluate the quality of methodology used on which these reference values are grounded, with the help of already established quality standards for research design, statistical analysis as well as methods of results reporting. The results found are considerably heterogenetic in terms of quality scoring of methodology in sonographic studies based on Doppler reference values of umbilical artery, and middle cerebroplacental artery. These variations could be due to the reference ranges reporting ways whereas these alterations in reporting also clarify few changes observed in the prenatal examination in terms of Doppler ${ }^{19-21,49}$ which also affects at perennial level. ${ }^{15,26}$

The current study has explored the potential risk of bias established on study design of the research publication and suitability of statistical analysis as well as its method of interpretation with the help of a predeveloped scoring sheet to rate quality of the research study methodology qualityscoring sheet of 22 standards to conclude the clinical management relevance of the study.

Eighty percent of the data was from prospective studies which was collected via clinical information collected regularly to make a reference might be significant cause of biasness, with higher depiction of cases which are at risk. Five research articles were conducted on unchecked populations. Population which is not predefined certifies a better demonstration of primary population. It was deliberated that the purpose of fetal Doppler chart should show that what are the optimal conditions as well as risk conditions of fetal hemodynamics ${ }^{50}$. All the studies were performed by one sonographer per study whereas two or more than two sonographer studies enhance the external validity of the results and consistency in data could be obtained by piloting before data collection ${ }^{51}$. Unavailability of blinding of researchers which was not present in any of the studies increase the risk of biasness whereas blinding is recommended by STROBE to reduce the biasness ${ }^{52}$. Data quality of ultrasound should be monitored via standard quality control strategy to reduce the risk of biasness while ensuring better quality and should preferably contain the usage of method of image scoring and the evaluation of intra-rater as well as interrater reliability of measurement ${ }^{53}$. Gestational age assessment should be precise as it a basic requirement for developing any fetal criteria ${ }^{54,55,57}$.

\section{CONCLUSION}

Rigorous methodology of this review study is the major strength, which is consisted of a standard and well developed methodology of scoring the quality of studies according to their methodology selection as well as the statistical analysis and the level of its interpretation. The quality assessment in percentages makes results interpretation more objective.

\section{REFERENCES}

1. Figueras F, Gardosi J. Intrauterine growth restriction: new concepts in antenatal surveillance, diagnosis, and management. $\mathrm{Am}$ JObstetGynecol 2011; 204: 288-300.

2. Simonazzi G, Curti A, Cattani L, Rizzo N, Pilu G Outcome of severe placental insufficiency with abnormal umbilical artery Doppler prior to fetal viability. BJOG 2013; 120: 754-757.

3. Hernandez-Andrade E, Serralde JA, Cruz-Martinez R. Can anomalies of fetal brain circulation be useful in the management of growth restricted fetuses? Prenat Diagn 2012; 32: 103-112.

4. Khali A, Thilaganathan B. Role of uteroplacental and fetal Doppler in identifying fetal growth restriction at term. Best Pract Res Clin Obstet Gynaecol 2017; 38: 38-47.

5. Harrington K, Carpenter RG, Nguyen M, Campbell S. Changes observed in Doppler studies of the fetal circulation in pregnancies complicated by pre-eclampsia or the delivery of a small for gestational age baby. I. Cross-sectional analysis. Ultrasound Obstet Gynecol 1995; 6: 19-28.

6. Baschat AA, Viscardi RM, Hussey-Gardner B, Hashmi N, Harman C. Infant neurodevelopment following fetal growth restriction: relationship with antepartum

7. surveillance parameters. Ultrasound Obstet Gynecol 2009; 33: 44-50.

8. Oros D, Figueras F, Cruz-Martinez R, Padilla N, Meler E, HernandezAndrade E, Gratac' os E. Middle vs anterior cerebral artery Doppler for the prediction of perinatal outcome and neonatal neurobehavior in term small-for-gestational-age fetuses with normal umbilical artery Doppler. Ultrasound Obstet Gynecol 2010; 35: 456-461.

9. Baschat AA. Neurodevelopment following fetal growth restriction and its relationship with antepartum parameters of placental dysfunction. Ultrasound Obstet Gynecol 2011; 37: 501-514.

10. Nassr AA, Abdelmagied AM, Shazly SA. Fetal cerebro-placental ratio and adverse perinatal outcome: systematic review and meta-analysis of the association and diagnostic performance. J PerinatMed 2016; 44: 249-256.

11. Khalil AA, Morales-Rosello J, Morlando $M$, Hannan $H$, Bhide $A$, Papageorghiou A, Thilaganathan $B$. Is fetal cerebroplacental ratio an independent predictor of intrapartum fetal compromise and neonatal unit admission? Am J Obstet Gynecol 2015; 213: 54.e1-10.

12. Cruz-Mart'ınez R, Figueras F, Hernandez-Andrade E, Oros D, Gratac os E. Fetal brain Doppler to predict Cesarean delivery for nonreassuring fetal status in term small-for-gestational-age fetuses. Obstet Gynecol 2011; 117: 618-626.

13. Garcia-Simon R, Figueras F, Savchev S, Fabre E, Gratac 'os E, Oros D. Cervical condition and fetal cerebral Doppler as determinants of adverse perinatal outcome after labor induction for late-onset smallfor-gestational-age fetuses. Ultrasound Obstet Gynecol 2015; 46: 713717.

14. Khalil AA, Morales-Rosello J, Elsaddig M, Khan N, Papageorghiou A, Bhide A, Thilaganathan B. The association between fetal Doppler and admission to neonatal unit at term. Am J Obstet Gynecol 2015; 213: 57.e1-7.

15. Khalil A, Morales-Rosello J, Khan N, Nath M, Agarwal P, Bhide A, Papageorghiou A, Thilaganathan $B$ Is cerebroplacental ratio a marker of impaired fetal growth velocity and adverse pregnancy outcome? Am J Obstet Gynecol 2017; 216: 606.e1-10

16. DeVore GR. The importance of the cerebroplacental ratio in the evaluation of fetal well-being in SGA and AGA fetuses. Am J Obstet Gynecol 2015; 213: 5-15.

17. Conde-Agudelo A, Villar J, Kennedy SH, Papageorghiou AT. Predictive accuracy of cerebroplacental ratio for adverse perinatal and neurodevelopmental outcomes in suspected fetal growth restriction: systematic review and meta-analysis. Ultrasound Obstet Gynecol 2018; 52: 430-441.

18. Bhide A, Acharya G, Bilardo CM, Brezinka C, Cafici D, HernandezAndrade E, Kalache K, Kingdom J, Kiserud T, Lee W, Lees C, Leung KY, Malinger G, Mari G, Prefumo F, Sepulveda W, Trudinger B. ISUOG practice guidelines: use of Doppler ultrasonography in obstetrics. Ultrasound Obstet Gynecol 2013; 41: 233-239.

19. Yoon BH, Romero R, Roh CR, Kim SH, Ager JW, Syn HC, Cotton D, Kim SW. Relationship between the fetal biophysical profile score, umbilical artery Doppler velocimetry, and fetal blood acid-base status determined by cordocentesis. Am J Obstet Gynecol 1993; 169: 15861594.

20. Unterscheider J, Daly S, Geary MP, Kennelly MM, McAuliffe FM O'Donoghue K, Hunter A, Morrison JJ, Burke G, Dicker P, Tully EC, Malone FD. Predictable progressive Doppler deterioration in IUGR: does it really exist? Am J Obstet Gynecol 2013; 209: 539.e1-7. 
21. Turan OM, Turan S, Gungor S, Berg C, Moyano D, Gembruch U, Nicolaides KH, Harman CR, Baschat AA. Progression of Doppler abnormalities in intrauterine growth restriction. Ultrasound Obstet Gynecol 2008; 32: 160-167.

22. Ferrazzi E, Bozzo M, Rigano S, Bellotti M, Morabito A, Pardi G, Battaglia FC, Galan HL. Temporal sequence of abnormal Doppler changes in the peripherals and central circulatory systems of the severely growth-restricted fetus. Ultrasound Obstet Gynecol 2002; 19: 140-146.

23. Oros D, Figueras F, Cruz-Martinez R, Meler E, Munmany M, Gratac os E. Longitudinal changes in uterine, umbilical and fetal cerebral Doppler indices in late-onset small-for-gestational age fetuses. Ultrasound Obstet Gynecol 2011; 37:191-195.

24. Lees C, Marlow N, Arabin B, Bilardo CM, Brezinka C, Derks JB, Duvekot J, Frusca T, Diemert A, Ferrazzi E, Ganzevoort W, Hecher K, Martinelli P, Ostermayer E, Papageorghiou AT, Schlembach D, Schneider KT, Thilaganathan B, Todros T, van Wassenaer-Leemhuis A, Valcamonico A, Visser $\mathrm{GH}$, Wolf $\mathrm{H}$; TRUFFLE Group. Perinatal morbidity and mortality in early-onset fetal growth restriction: cohort outcomes of the trial of randomized umbilical and fetal flow in Europe (TRUFFLE). Ultrasound Obstet Gynecol 2013; 42: 400-408.

25. Thornton JG, Hornbuckle J, Vail A, Spiegelhalter DJ, Levene M; GRIT study group. Infant wellbeing at 2 years of age in the Growth Restriction Intervention Trial (GRIT): multicentred randomised controlled trial. Lancet 2004; 364: 513-520.

26. Caradeux J, Martinez-Portilla RJ, Basuki TR, Kiserud T, Figueras F. Risk of fetal death in growth-restricted fetuses with umbilical and/or ductus venosus absent or reversed end-diastolic velocities before 34 weeks of gestation: a systematic review and meta-analysis. $A m ~ J$ Obstet Gynecol 2018; 218: S774-782.e21.

27. Morris RK, Say R, Robson SC, Kleijnen J, Khan KS. Systematic review and meta-analysis of middle cerebral artery Doppler to predict perinatal wellbeing. Eur J Obstet Gynecol Reprod Biol 2012; 165: 141 155.

28. Stampalija T, Arabin B, Wolf H, Bilardo CM, Lees C; TRUFFLE investigators. Is middle cerebral artery Doppler related to neonatal and 2-year infant outcome in early fetal growth restriction? Am J Obstet Gynecol 2017; 216: 521.e1-13. Erratum in: Am J Obstet Gynecol 2017; 216: 522 .

29. Alfirevic Z, Stampalija T, Medley N. Fetal and umbilical Doppler ultrasound in normal pregnancy. Cochrane Database Syst Rev 2015; Issue 4: CD001450.

30. D'Antonio F, Patel D, Chandrasekharan N, Thilaganathan B, Bhide A Role of cerebroplacental ratio for fetal assessment in prolonged pregnancy. Ultrasound Obstet Gynecol 2013; 42: 196-200.

31. Graves CR. Antepartum fetal surveillance and timing of delivery in the pregnancy complicated by diabetes mellitus. Clin Obstet Gynecol 2007; 50: 1007-1013.

32. Vayssi ere C, Benoist G, Blondel B, Deruelle P, Favre R, Gallot D, Jabert P, Lemery D, Picone O, Pons JC, Puech F, Quarello E Salomon L, Schmitz T, Senat MV, Sentilhes L, Simon A, Stirneman J, Vendittelli F, Winer N, Ville Y; French College of Gynaecologists and Obstetricians. Twin pregnancies: guidelines for clinical practice from the French College of Gynaecologists and Obstetricians (CNGOF). Eur J Obstet Gynecol Reprod Biol 2011; 156: 12-17.

33. American College of Obstetricians and Gynecologists. ACOG Practice bulletin no. 134: fetal growth restriction. Obstet Gynecol 2013; 121: 1122-1133.

34. Ioannou C, Talbot K, Ohuma E, Sarris I, Villar J, Conde-Agudelo A, Papageorghiou AT. Systematic review of methodology used in ultrasound studies aimed at creating charts of fetal size. BJOG 2012; 119: 1425-1439

35. Stroup DF, Berlin JA, Morton SC, Olkin I, Williamson GD, Rennie D, Moher D, Becker BJ, Sipe TA, Thacker SB. Meta-analysis of observational studies in epidemiology: a proposal for reporting. Metaanalysis of observational studies in epidemiology (MOOSE) group. $J$ Am Med Assoc 2000; 283: 2008-2012.

36. Liberati A, Altman DG, Tetzlaff J, Mulrow C, Gøtzsche PC, loannidis JP, Clarke M, Devereaux PJ, Kleijnen J, Moher D. The PRISMA statement for reporting systematic reviews and meta-analyses of studies that evaluate healthcare interventions: explanation and elaboration. BMJ 2009; 339: b2700.

37. Napolitano R, Dhami J, Ohuma EO, Ioannou C, Conde-Agudelo A, Kennedy SH, Villar J, Papageorghiou AT. Pregnancy dating by fetal crown-rump length: a systematic review of charts. BJOG 2014; 121 556-565.

38. Oros D, Ruiz, Martinez S, Staines Urias E, Conde, Agudelo A, Villar J, Fabre $\mathrm{E}$ et al. Reference ranges for Doppler indices of umbilical and fetal middle cerebral arteries and cerebroplacental ratio: systematic review. Ultrasound in Obstetrics \& Gynecology. 2019;53(4):454-464.

39. Srikumar S, Debnath J, Ravikumar R, Bandhu H, Maurya V. Doppler indices of the umbilical and fetal middle cerebral artery at 18-40 weeks of normal gestation: A pilot study. Medical Journal Armed Forces India. 2017;73(3):232-241.

40. Zohav E, Zohav E, Rabinovich M, Alasbah A, Shenhav S, Sofer H et al. Third-trimester Reference Ranges for Cerebroplacental Ratio, Middle Cerebral Artery, and Umbilical Artery Pulsatility Index in Normal-growth Singleton Fetuses in the Israeli Population. Rambam Maimonides Medical Journal. 2019;10(4):e0025

41. Vollgraff Heidweiller-Schreurs $C$, De Boer $M$, Heymans $M$, Schoonmade L, Bossuyt P, Mol B et al. Prognostic accuracy of cerebroplacental ratio and middle cerebral artery Doppler for adverse perinatal outcome: systematic review and meta-analysis. Ultrasound in Obstetrics \& Gynecology. 2018;51(3):313-322.

42. Kim S, Paek M, Ko I. Diagnosis of fetal asphyxia depending on the change of blood flow of fetal middle cerebral artery and umbilical artery using color Doppler ultrasonography. Medical Journal of Dr DY Patil Vidyapeeth. 2020;13(5):552.

43. Ciobanu A, Wright A, Syngelaki A, Wright D, Akolekar R, Nicolaides K. Fetal Medicine Foundation reference ranges for umbilical artery and middle cerebral artery pulsatility index and cerebroplacental ratio. Ultrasound in Obstetrics \& Gynecology. 2019;53(4):465-472.

44. Masihi S, Nikbakht R, Barati M, Momen Gharibvand M, Jadidi A. Association Between Fetal Middle Cerebral Artery and Umbilical Artery Doppler Ratio with Fetal Distress in 38-40 Weeks of Gestation. The Journal of Obstetrics and Gynecology of India. 2019;69(6):509-513.

45. Flatley C, Kumar S, Greer R. Reference centiles for the middle cerebral artery and umbilical artery pulsatility index and cerebroplacental ratio from a low-risk population - a Generalised Additive Model for Location, Shape and Scale (GAMLSS) approach. The Journal of Maternal-Fetal \& Neonatal Medicine. 2018;32(14):23382345

46. Widnes C, Flo K, Wilsgaard T, Kiserud T, Acharya G. Sex differences in umbilical artery Doppler indices: a longitudinal study. Biology of Sex Differences. 2018:9(1).

47. Awowole I, Kuti O, Asaleye C, Badejoko O, Bola- Oyebamiji S, Olatunji $\mathrm{R}$ et al. Normative references and clinical correlates of fetal umbilical artery Doppler indices in southwestern Nigeria. International Journal of Gynecology \& Obstetrics. 2020;151(1):134-140.

48. Leavitt K, Odibo L, Nwabuobi C, Tuuli M, Odibo A. The value of introducing cerebroplacental ratio (CPR) versus umbilical artery (UA) Doppler alone for the prediction of neonatal small for gestational age (SGA) and short-term adverse outcomes. The Journal of MaternalFetal \& Neonatal Medicine. 2019;:1-5.

49. Wladimiroff JW, Noordam MJ, van den Wijngaard JA, Hop WC. Fetal internal carotid and umbilical artery blood flow velocity waveforms as a measure of fetal well-being in intrauterine growth retardation. Pediatr Res 1988; 24: 609-612.

50. Rasmussen S. Charts to assess fetal wellbeing. Ultrasound Obstet Gynecol 2011; 37: 2-5.

51. de Onis M, Garza C, Victora CG, Onyango AW, Frongillo EA, Martines J. The WHO multicentre growth reference study: planning, study design and methodology. Food Nutr Bull 2004; 25: S15-26.

52. Hr' objartsson A, Thomsen AS, Emanuelsson F, Tendal B, Hilden J, Boutron I, Ravaud P, Brorson S. Observer bias in randomised clinical trials with binary outcomes: systematic review of trials with both blinded and non-blinded outcome assessors. BMJ 2012; 344: e1119.

53. Vandenbroucke JP, von Elm E, Altman DG, Gøtzsche PC, Mulrow CD, Pocock SJ, Poole C, Schlesselman JJ, Egger M; STROBE Initiative. Strengthening the Reporting of Observational Studies in Epidemiology (STROBE): explanation and elaboration. PLoS Med 2007; 4: e297.

54. Capmas P, Salomon LJ, Picone O, Fuchs F, Frydman R, Senat MV Using Z-scores to compare biometry data obtained during prenatal ultrasound screening by midwives and physicians. Prenat Diagn 2010; 30: 40-42.

55. Salomon LJ, Bernard JP, Duyme M, Buvat I and Ville Y. The impact of choice of reference charts and equations on the assessment of fetal biometry. Ultrasound Obstet Gynecol 2005; 25: 559-565.

56. Ruiz-Martinez S, Volpe G, Vannuccini S, Cavallaro A, Impey LW, Papageorghiou AT. An objective system to evaluate the quality of middle cerebral artery Doppler images. Abstracts of the 27th World Congress of the International Society of Ultrasound in Obstetrics and Gynecology. Ultrasound Obstet Gynecol 2017; 50: 235.

57. Gardosi J. Dating of pregnancy: time to forget the last menstrual period. Ultrasound Obstet Gynecol 1997; 9:367-368. 